\title{
Counter immunoelectrophoresis as a rapid screening test for amoebic liver abscess
}

\author{
JENNIFER HC TOSSWILL, DS RIDLEY, AND DC WARHURST \\ From the Amoebiasis Unit, Department of Pathology, Hospital for Tropical Diseases, 4 St Pancras Way, \\ London NWI OPE, UK
}

SUMMARY Counter immunoelectrophoresis using cellulose acetate as the supporting medium was used as a rapid screening test for amoebic abscess. All the sera from 40 cases gave positive results. No false positives were obtained, but the results in intestinal amoebiasis were less reliable. An attempt was made to account for discrepancies in previous reports.

Although the use of counter immunoelectrophoresis (CIEP) in the diagnosis of amoebiasis has been well documented, reports of the reliability of the test have not been unanimous. ${ }^{1-8}$ However, it appears to offer the prospect of being a useful screening test for amoebic abscess, for which there is a need. Studies so far have been carried out using agar or agarose as the supporting medium, though Stamm, Phillips, and Warhurst (unpublished observations) carried out promising preliminary tests with cellulose acetate membrane. From the point of view of a rapid screening test, cellulose acetate provides a more rapid diffusion medium than gel; it is also more standardised and easier to handle.

The purpose of this paper is to evalute the cellulose acetate CIEP test and to seek the causes of discrepancies in previously reported results.

\section{Material and methods}

SER A

Sera were available from 40 patients with confirmed amoebic liver abscess and from three with amoeboma of the colon. About half the patients were in the Hospital for Tropical Diseases, while other sera were referred to the department from outside sources. A systematic study of amoebic dysentery was not possible, but 13 patients with intestinal symptoms and a positive immunofluorescent test were included. As controls, sera were tested from 50 patients attending the hospital for tropical investigations who were thought not to have amoebiasis, and from $\mathbf{5 0}$ patients attending an antenatal clinic. The sera were not inactivated but stored at $-20^{\circ} \mathrm{C}$ for a maximum period of six months.

Received for publication 2 August 1979
ANTIGEN

A lyophilised preparation of Entamoeba histolytica strain HK9 amoeba grown in TPS-1,9 was kindly supplied to the Amoebiasis Unit by Dr E M Proctor. The powder was dissolved in distilled water at a concentration of $13.2 \mathrm{mg} / \mathrm{ml}\left(10^{7}\right.$ amoebae $/ \mathrm{ml}$ ) and freeze-thawed three times. The turbid solution was lyophilised in $0.1 \mathrm{ml}$ aliquots for storage at $-20^{\circ} \mathrm{C}$. Each ampoule was reconstituted with $0.1 \mathrm{ml}$ distilled water. The antigen was subsequently diluted for use, as described below. It could be stored in diluted form at $-20^{\circ} \mathrm{C}$ for up to 12 days. CIEP has also been carried out with antigen prepared similarly from $E$. histolytica strain NIH200, which appears to give identical results.

\section{COUNTER IMMUNOELECTROPHORESIS}

CIEP was carried out on cellulose acetate membrane (Shandon CELAGRAM strip) using Tris-barbitalsodium-barbital buffer ( $\mathrm{pH} \mathrm{8.8)}$ ionic strength 0.06 in a Gelman chamber. The paper was floated on the buffer and gently blotted. Using a Perspex template and rounded metal rod, two parallel rows of equally spaced indentations, $3 \mathrm{~mm}$ in diameter, were made on the paper strip, $80 \mathrm{~mm}$ and $93 \mathrm{~mm}$ from one end. A strip measuring $78 \times 150 \mathrm{~mm}$ accommodated three indentations in each row. Each strip was supported by the two bridges in the tank and held in place with the aid of four magnets. The wells were nearer the cathode end. Equilibration was carried out at a constant voltage of $200 \mathrm{~V}$, giving a current of $2 \mathrm{~mA}$ per strip, for 2 minutes. Then $4 \mu$ l of each test serum was placed in the anodal wells. It was found by experiment that a 1/10 dilution of the antigen in PBS (pH 7.6) was optimal. The diluted antigen was placed in each of the wells nearer the cathode. The current was then reconnected, and after 35 minutes 
at room temperature the strips were removed from the chamber and washed by shaking in a saline bath for 10 to 15 minutes. The strips were stained for 5 minutes in Nigrosin ${ }^{10}$ and washed for 1 minute in tap water. A positive result was indicated by the presence of one or more precipitin lines between antigen and serum wells when the wet strip was held against a bright light source.

The amoebiasis sera were all tested for comparison by immunofluorescence (IFAT) and cellulose acetate precipitation (CAP). ${ }^{10}$

\section{Results}

The results are summarised in Table 1 . The specificity of CIEP was found to be high, as no false-positive results were obtained in the 100 sera taken from patients without evidence of amoebiasis. The sensitivity of the test in detecting liver abscess and amoeboma was also $100 \%$. However, the CIEP was found to be considerably less reliable in cases of invasive intestinal amoebiasis, in which only $61 \%$ of cases which had given positive results by IFAT were positive by CIEP.

Table 1 CIEP positivity in patients with and without amoebiasis

\begin{tabular}{lccc}
\hline & $\begin{array}{l}\text { No. of } \\
\text { cases }\end{array}$ & No. positive & $\%$ positive \\
\hline Amoebiasis & & & \\
$\quad$ Liver abscess & 40 & 40 & 100 \\
Amoeboma & 3 & 3 & 100 \\
$\quad$ Intestinal & 13 & 8 & 61 \\
Controls, normal & 50 & 0 & 0 \\
Controls, tropical patients & 50 & 0 & 0 \\
\hline
\end{tabular}

All the amoebiasis sera were found to be positive by IFAT and CAP, with the exception of two cases of intestinal amoebiasis which were negative by CAP.

Tests were carried out to determine the effect of storage of serum and antigen on CIEP. Two out of 21 sera from patients with hepatic abscess were found to be negative after storage at $-20^{\circ} \mathrm{C}$ for six to 18 months, although no noticeable fall in titre was detected by IFAT. It was also found that diluted antigen which had been stored at $-20^{\circ} \mathrm{C}$ at the working dilution for more than about 12 days produced negative results in a high proportion of cases.

\section{Discussion}

The CIEP test has been found to be a reliable screening test for amoebic liver abscess both in our experience and in that of Krupp, ${ }^{2}$ combining a
$100 \%$ positivity rate with an absence of false positives. Of all the parasitic infections for which serodiagnosis is employed amoebic abscess is the one in which the greatest weight is placed on the serological result. Amoeboma is perhaps second in medical or surgical importance, and again alternative methods of diagnosis are unreliable. These two conditions are also those in which serology is most likely to be requested as an emergency. CIEP would appear to be the test of choice. All previous work with this test has been based on agarose gel as the diffusion medium. The cellulose acetate membrane used in the present study is simpler to prepare, it is completely standardised, and the test can be completed and read in 1 hour.

The question arises why several other workers have obtained less good results (Table 2). One possibility is the inadequacy of some preparations of agar gel. The results reported here indicate also the importance of using freshly diluted amoebic antigen (not more than 12 days old). Results were also less good with serum stored at $-20^{\circ} \mathrm{C}$.

Table 2 Summary of previous reports of the use of CIEP in amoebiasis

\begin{tabular}{lccl}
\hline Reference No. & \multicolumn{2}{c}{$\%$ Positivity } & $\%$ False positive \\
\cline { 2 - 3 } & \multicolumn{1}{c}{ Abscess } & Intestinal & \\
\hline 1 (quoted by 5) & 98 & - & $5 \cdot 8$ \\
2 & 100 & 96 & 0 \\
3 & 95 & - & $1 \cdot 7$ \\
4 & 93 & 95 & $2 \cdot 5$ \\
5 & 100 & 88 & 0 \\
6 & 89 & -1 & - \\
7 & - & 21 & -16 \\
8 & 84 & 18 & 36 \\
\hline
\end{tabular}

CIEP was found to be less sensitive than IFAT and more sensitive than CAP. IFAT remains the first choice as a general screening test, partly for its sensitivity and partly because it is well suited to large-scale operations. But IFAT positivity needs to be checked by CAP. None of these tests has given reliable results with invasive intestinal amoebiasis, and CIEP is not recommended in this situation.

We thank Dr A L Jeanes for supplying nine sera from patients with proven amoebic liver abscess. The Amoebiasis Unit is supported by the Public Health Laboratory Service.

\section{References}

'Sepulveda B, Aubanel M, Landa L, Velasques G. Avances en la técnica de contra-immunoelectroforesis para el estudio serológico de la amibiasis. Arch Invest Med (Mex) 1972; 3: Suppl. 2; 363-370. 
${ }^{2}$ Krupp I M. Comparison of counterimmunoelectrophoresis with other serological tests in the diagnosis of amebiasis. Am J Trop Med 1974; 23 : 27-30.

${ }^{3}$ Mahajan R C, Ganguly N K, Chitkara N L. Counterimmunoelectrophoresis for rapid serodiagnosis of amoebic liver abscess. Indian J Med Res 1975; 63: 54-57.

${ }^{4}$ Mahajan R C, Ganguli N K, Chhabra M B, Chitkaro $\mathbf{N}$, Chatani $\mathbf{P}$ N. Evaluation of serameba, counter-immunoelectrophoresis and bentonite flocculation test in rapid diagnosis of invasive amoebiasis. Indian J Pathol Microbiol 1976; 19: 123-126.

${ }^{5}$ Alper E I, Littler C, Monroe L S. Counterelectrophoresis in the diagnosis of amebiasis. Am J Gastroenterol 1976; 65: 65-67.

${ }^{6}$ Farid Z, Hassan A, Trabolsi B, Higashi G I, Mansour N S, Miner W F. Hepatic amebiasis; diagnostic counterimmunoelectrophoresis and metronidazole (Flagyl) therapy. Am J Trop Med Hyg 1977; 26: 822-823.
${ }^{7}$ Martuscelli-Q A, Hernández Gonzalez A, Zúñiga Telleria V. Evolución de la reacción de contrainmunoelectroforesis en niños con amibiasis intestinal aguda. Rev Invest Salud Publica 1977; 37: 93-99.

${ }^{8}$ Mannweiler E, Lederer I. Immunodiagnostische Ergebnisse bei der Amöbiasis. Die Leistung der Gegenström-immunelectrophorese im Vergleich zu drei anderen Immuntests. Zentralb Bakteriol [Orig A] $1978 ; 240$ : 403-408.

${ }^{9}$ Diamond L S. Techniques of axenic cultivation of Entamoeba histolytica Schaudinn 1903 and E histolytica like amebae. J Parasitol 1968; 54: 1047-1056.

${ }^{10}$ Stamm W P, Phillips E A. A cellulose acetate membrane precipitin (CAP) test for amoebiasis. Trans $R$ Soc Trop Med Hyg 1977; 71: 490-492.

Requests for reprints to: JHC Tosswill, Department of Serology, Hospital for Tropical Diseases, $4 \mathrm{St}$ Pancras Way, London NW1 OPE, UK. 